\title{
LA IDONEIDAD DE LA TÉCNICA PROCESAL: UNA RELECTURA DE LA TUTELA JURISDICCIONAL EFECTIVA
}

\author{
THE SUITABILITY OF THE PROCEDURAL TECHNIQUE: A \\ REVIEW OF THE EFFECTIVE JURISDICTIONAL PROTECTION
}

PABLO MARTÍNEZ ZÚÑIGA***

\section{RESUMEN}

La tutela jurisdiccional efectiva y la eficiencia procesal son conceptos que están en directa relación e interactúan en favor de la protección de los derechos materiales e intereses, fin de la Jurisdicción en un Estado de Derecho Constitucional. La técnica procesal idónea o adecuada, aparece como una variable para la eficiencia concreta. La textura abierta o porosa de las normas constitucionales chilenas que regulan la materia hoy, permiten releer su contenido e integrar esta propuesta que al final de la investigación termina siendo considerada condición y presupuesto de la misma. La integración de estos conceptos encuentra además respaldo suficiente por la doctrina nacional y comparada desde la evolución de la tutela cautelar hasta la aparición de nuevas formas procesales como las tutelas diferenciadas. La idoneidad de la técnica procesal en tal sentido aparece como una herramienta clave para el fin, incluso sin necesidad de reformas legales.

*Profesor asistente de Derecho Procesal, Universidad Católica del Norte, Coquimbo, Chile. Abogado, Licenciado en Ciencias Jurídicas y Sociales, Universidad de Concepción. Magíster en Derecho, Pontificia Universidad Católica de Valparaíso, y candidato a Dr. en Derecho, Universidad Austral de Buenos Aires, Argentina. Correo: pablo.martinez@ucn.cl. ORCID: https://orcid.org/0000-00029448-9737.

**Abreviaturas: TJE: Tutela jurisdiccional efectiva, CPR: Constitución Política de la República de Chile, CPC: Código de Procedimiento Civil, CS: Corte Suprema, TC: Tribunal Constitucional de Chile, CT: Código del Trabajo.

Trabajo recibido el 24 de noviembre de 2020 y aceptado para su publicación el 13 de diciembre de 2021 . 
Palabras clave: Tutela jurisdiccional, Efectividad jurisdiccional, Eficiencia procesal, Técnica procesal, Tutela procesal, Tutela jurisdiccional efectiva.

\section{ABSTRACT}

Effective jurisdictional protection and procedural efficiency are concepts that are directly related and interact in favor of the protection of material rights and interests, the end of the Jurisdiction in a State of Constitutional Law. The ideal or adequate procedural technique appears as a variable for concrete efficiency. The open or porous texture of the Chilean constitutional norms that regulate the matter today, allow to reread its content and integrate this proposal that at the end of the investigation ends up being considered a condition and presupposition of the same. The integration of these concepts is also sufficiently supported by national and comparative doctrine from the evolution of precautionary protection to the appearance of new procedural forms such as differentiated techniques. The suitability of the procedural technique in this regard appears as a key tool for the purpose, even without the need for legal reforms.

Keywords: Jurisdictional protection, Jurisdictional effectiveness, Procedural technique, Procedural efficiency, Procedural protection, Effective jurisdictional protection.

\section{INTRODUCCIÓN}

\subsection{El propósito de este trabajo}

La técnica procesal y su adecuación e idoneidad a los derechos e intereses cuya tutela se persigue debe ser incorporada al concepto de tutela jurisdiccional efectiva. No solo eso, dado el actual entendimiento de las normas procesales, conectadas y al servicio de las normas materiales y derecho procesal, la hacen un presupuesto de la promesa de efectividad.

Propondremos en este sentido, dos adjetivos cargados de un objetivo correctivo u axiológico: la idoneidad de la técnica procesal como medio eficiente para el fin de efectividad perseguido.

Para corroborar estas afirmaciones, cuestionaremos el sesgo 
economicista de la eficiencia procesal, sobre la cual descansan los esfuerzos en torno a la mejora de los sistemas de justicia. Propondremos entonces, a la idoneidad de la técnica procesal como una variable mucho más concreta y manejable de esta eficiencia.

Analizaremos nuestra regulación actual sobre Tutela Jurisdiccional Efectiva (en adelante, TJE) para develar la ductilidad y porosidad de sus normas. Esto nos permitirá promover un lugar dentro de este universo categorial a nuestra propuesta, auxiliados sobre todo por el empuje de la doctrina comparada, que paso a paso la ha ido promocionando, dada la evolución post cautelar y el avance de las tutelas procesales diferenciadas.

\subsection{Una prevención epistemológica}

Es importante tener presente, que las ideas que siguen asumen como eje argumental, un análisis parcelado de la efectividad de los derechos; su reconocimiento por vía jurisdiccional.

Es posible, sin duda, una mirada en un plano mayor o diferente, donde la efectividad de los derechos puede verificarse mediante el ejercicio de otras potestades públicas que hacen actuar el derecho, como la administrativa, e incluso sin la necesidad de las mismas. Sin embargo, siempre que se escriba sobre esto, se estará tomando alguna posición teórica sobre la eficacia y efectividad del ordenamiento jurídico. Todas perfectamente argumentables, ninguna prevalente. La discusión centenaria excede al presente trabajo, y es propia de la Filosofía del Derecho, pero es necesario transparentar nuestra concepción teórica sobre el punto.

Adherimos en esta investigación al concepto de efectividad que Ross formuló al expresar sus ideas sobre la vigencia del derecho. ${ }^{1}$ Esto es, la vigencia de un determinando sistema u ordenamiento está en la idea de efectividad. Siempre desde la realidad, mirado por un observador externo, pero también desde lo interno, en tanto la regla es vivida como socialmente obligatoria y se actúa en consecuencia a ella. "El derecho presupone la regularidad en el comportamiento del Juez"2 al hablar de fuerza y validez del derecho. La vigencia de éste involucra dos cuestiones: el acatamiento

\footnotetext{
${ }^{1}$ Ross, Alf, Sobre el derecho y la justicia, Universidad de Buenos Aires, Buenos Aires, 1977, $4^{\circ}$ ed., trad. de CARrió, Genaro, p. 17.

${ }^{2}$ Ross, cit. (n. 1), pp. 33 y 35.
} 
regular y externamente observable de una pauta de acción y la experiencia de esa pauta como norma obligatoria. El derecho vigente debe ser vivido como socialmente obligatorio. La vigencia del derecho no puede apoyarse en una visión puramente conductista. ${ }^{3}$ Así, el derecho es un conjunto de reglas concernientes al ejercicio de la fuerza física ejercida institucionalmente por orden, a su vez, de normas jurídicas creadas por los órganos jurisdiccionales. ${ }^{4}$

En el mismo sentido CAPELla advierte que "La eficacia de una norma respecto de un fenómeno jurídico empírico determinado se entiende como la capacidad de la norma para funcionar como determinante de causa de tal fenómeno. Es eficaz $x$ norma porque es lo que determina que pase $y$ ". $5 \mathrm{Se}$ refiere entonces una relación material que mira el impacto de las normas jurídicas en cuanto al "universo social"" (o realidad).

Por su parte, la efectividad sería "una especie de eficacia particular, exclusivamente institucional". ${ }^{7}$ Es decir, la norma es efectiva a su vez cuando es obedecida y aplicada por los órganos del poder público. Esta institucionalidad en la instauración de hecho de las normas jurídicas supone desde luego la potestad pública por excelencia encargada de esa tarea: la jurisdicción. ${ }^{8}$

\section{TUTELA JURISDICCIONAL EFECTIVA Y EFICIENCIA PROCESAL}

Situados en la nomenclatura procesal contemporánea escrita en clave de tutela de los derechos y de manera más explícita en clave de protección judicial de esos derechos como función y el fin de la jurisdicción, no puede negarse la trascendencia del adjetivo calificativo que acompaña a la tutela jurisdiccional en el foro, la doctrina y en la jurisprudencia: la efectividad.

La afirmación sobre la efectividad de los derechos y de que esto ha de

\footnotetext{
${ }^{3}$ Ross, cit. (n. 1), pp. 51.

${ }^{4}$ VIGO, Rodolfo, Perspectivas Iusfilosóficas Contemporáneas, Abeledo-Perrot, Buenos Aires, 2019, $3^{\circ}$ ed., pp. 20-24.

${ }^{5}$ Capella, Juan Ramón, Elementos de Análisis Jurídico, Trotta, Madrid, 2006, pp. 84-90.

${ }^{6}$ Capella, cit. (n. 5), p. 85

${ }^{7}$ Capella, cit. (n. 5), p. 87

${ }^{8}$ A contrario de estas líneas argumentales puede verse a propósito de la efectividad de los derechos con independencia del concepto de tutela jurisdiccional: Andrej Auersperger Matic, Just Words: The Effectiveness of Civil Justice in European Human Rights Jurisprudence, Cambridge, 2020.
} 
lograrse en términos no voluntarios por vía jurisdicciona $l^{9}$ es una afirmación de tipo deóntico. Lo que la sociedad toda quiere correctivamente que sea, no sólo lo que es.

En este orden de cosas, la eficiencia procesal juega un rol primordial respecto de la efectividad de la tutela jurisdiccional. El desenvolvimiento de ésta a efectos de poder prestarse en términos de derecho fundamental concreto, ${ }^{10}$ supone necesariamente que se inmiscuya este concepto en la técnica procesal ${ }^{11}$ utilizada tanto por el legislador como por el juez al momento de la substanciación de un caso concreto.

No cabe duda alguna que la eficiencia no es un concepto jurídico. Digo lo anterior porque desde la doctrina del análisis económico del derecho (AED) la eficiencia se erige como uno de sus pilares fundamentales. POSNER abre fuegos en su clásica obra señalando que los conceptos a utilizar son los de valor, utilidad y eficiencia. ${ }^{12}$ Para esta doctrina la eficiencia supone la asignación de recursos en la que se maximiza el valor, reconociéndose sin embargo las limitaciones de esto a la hora de la toma de decisiones sociales. ${ }^{13}$

Se trata de un concepto elemental para este enfoque teórico, que se traduce en la asignación de recursos (escasos) versus la maximización de la utilidad o riqueza, ${ }^{14}$ reconociendo eso sí, las limitaciones y la indiferencia del enfoque económico para con la justicia y a los principios de equidad, tanto respecto del servicio judicial como de su respuesta.

Estas nociones, que sin duda son de utilidad porque explicitan muy bien el fin de aprovechar al máximo posible los recursos disponibles, no reflejan el completo sentido que le da la realidad a la eficiencia procesal. Que todas las personas tomen sus decisiones con la finalidad de maximizar

\footnotetext{
${ }^{9}$ BArona, Silvia, "A la búsqueda de la eficiencia y celeridad, claves de la justicia civil del siglo XXI", Libro homenaje al profesor Fábrega, Instituto colombo-panameño de Derecho Procesal, 2019, en http://dx.doi.org/10.2139/ssrn.3511153, consultada: 26 de agosto de 2020.

${ }^{10}$ DE LA Oliva, Andrés, Sobre el derecho a la tutela jurisdiccional. La persona ante la administración de justicia, derechos básicos, Bosch, Barcelona, 1980, p. 24.

${ }^{11}$ Marinoni, Luiz Guilherme, Técnica processual e tutela dos direitos, Thomson Reuters Brasil, São Paulo, 2019, $6^{\circ}$ ed. en e-book basado en $6^{\circ}$ ed., RB-8.8.

${ }^{12}$ Posner, Richard, El análisis económico del derecho, trad. de SuÁrez, Eduardo, Fondo de Cultura Económica, Ciudad de México, 2007, p. 37.

${ }^{13}$ Posner, cit. (n. 12), p. 57.

${ }^{14}$ Stordeur, Eduardo, Análisis económico del derecho. Una introducción, Abeledo Perrot, Buenos Aires, 2011, p. 20.
} 
su utilidad o satisfacción, es un estado de cosas supuesto por el AED, que es perfectamente cuestionable y escapa a las posibilidades del conocimiento humano comprobar que ese enunciado se dé respecto de los justiciables a todo evento. La eficiencia no es tan fría ni tan compleja, está asentada en el ideario procesal, incluso fuera del AED. La prestación jurisdiccional como derecho fundamental es una actividad humana cuya función es la materialización de los derechos de las personas. Este volver hacia la justicia "de carne y hueso"15 supone utilizar a las ciencias auxiliares para ese fin, pero no transformar al derecho en una más de esas ciencias auxiliares.

Prefiero entonces, valernos de otra base epistemológica para postular una relectura de la eficiencia procesal. En este sentido, Ramón GARCíA, propone una categorización inicial de la eficiencia, a la vez que una propuesta de contenido de la misma.

El principio de eficiencia debe ser "instrumental en la consecución de los fines del proceso (...) y debe estar al servicio del sistema de justicia, de sus valores y objetivos, esto supone un consenso sobre cuales son ellos y explicitarlos tanto como sea posible. Mientras más claros sean ellos, se orienta mejor la gestión necesaria para alcanzar la eficiencia". ${ }^{16}$

Se compondría entonces de una doble finalidad axiológica o ética (lo que corrobora esta nota esencial que hemos venido anunciando) en cuanto a la "correcta utilización de los recursos públicos y asegurar una medida de justicia a todos los justiciables". ${ }^{17}$ Claramente la teoría económica no logra captar este último objetivo en toda su dimensión.

TARUFFo y ORTElls coinciden, en que la eficiencia debe apuntar a los fines del proceso civil, vinculando este concepto a la duración razonable del proceso, costes y calidad de la decisión ${ }^{18}$. Es decir, en general los autores que han escrito sobre el tema han puesto de relieve, ideas símiles sobre la identidad del porqué, del theos que debe perseguir la eficiencia como principio.

Así, es posible categorizar planos de eficiencia procesal. TARUFFO distingue dos niveles, el institucional y el concreto. ${ }^{19}$ Digamos desde ya,

\footnotetext{
${ }^{15}$ Marinoni, cit. (n. 11) RB-5.2.

${ }^{16}$ García, Ramón, Case Management, Tirant lo Blanch, Santiago de Chile, 2020, p. 244.

${ }^{17}$ García, cit. (n. 16), p. 249.

${ }^{18}$ García, cit. (n. 16), p. 73.

${ }^{19}$ Taruffo, Michele, Páginas sobre justicia civil, Trad. de Aramburo Calle, Maximiliano, Marcial
} 
que en este trabajo estamos particularmente interesados por el concreto. Respecto del institucional, BERIZONCE a su vez nombra subniveles como la orgánica de la administración de justicia, los modelos procesales, el auxilio a las partes en términos de defensa, disposición de peritos, colaboradores, infraestructura, entre otros. ${ }^{20}$

En cuento al plano concreto, aquello supone la puesta en práctica de legalidad orgánica y funciona cuya orientación propende hacia el fin de efectividad. Esto supone entonces, calidad en la formación de la ley procesal, pero sobre todo la tarea adecuada de interpretación y aplicación de estas reglas por parte de los y las juezas en los procesos vivos, en la litis concreta. $^{21}$

Mi propuesta es un tanto más modesta. Siempre desde la perspectiva concreta, mirar hacia una categoría clásica, pero desatendida, y que bien puede ser herramienta para contribuir a concretar tempestividad y costes como dos de los ejes de la nueva tridimensionalidad de los fines del proceso, ${ }^{22}$ pues se trata de una variable manejable, moldeable, por el legislador, el juez y el operador jurídico. Usaremos en este sentido, una expresión que creemos se aviene mejor al objeto pretendido: la idoneidad o adecuación ${ }^{23} \mathrm{de}$ la técnica o diseño procesal. Es una propuesta para erradicar el dejo economicista del eficientismo y revalorar la diferencia entre los justiciables, a efectos de lograr la conexión o puente entre el derecho material y el derecho procesal, funcionalmente dispuesto a la verificación del primero en la realidad. ${ }^{24}$

Afirmo en definitiva y me avocaré a ello en las páginas que siguen, que la idoneidad del diseño o estructura procesal es una herramienta que debe operar funcionalmente hacia la efectividad de la TJE y que hoy podemos leerla perfectamente como parte de su contenido. La tarea en lo inmediato es demostrar que dentro de este ajado binomio iusfundamental tiene cabida este elemento necesario y condicionante para el fin prometido por la actividad

\footnotetext{
Pons, Madrid, 2009, pp. 68-69.

${ }^{20}$ Berizonce, Omar, "Nuevos principios procesales y su recepción en ordenamientos jurídico-nacionales (influencia del derecho internacional y los derechos humanos)", Anales de la Facultad de Ciencias Jurídicas y Sociales de la Universidad Nacional de la Plata, 2012, $\mathrm{N}^{\circ}$ 42-9, pp. 257-289.

${ }^{21}$ García, cit. (n. 16) p. 251.

${ }^{22}$ García, cit. (n. 16) p. 187-208.

${ }^{23}$ Marinoni, cit. (n. 11) RB-8.8.

${ }^{24}$ Pérez, Álvaro, "Diálogo entre los derechos sustantivo y procesal: el puente de la justicia procedimental", en Priori, G. (coord.), Derecho Material y proceso, Palestra, Lima, 2017, pp. 57-80.
} 
jurisdiccional: la verificación en la realidad de las normas materiales.

\section{LAS NOTAS DE NUESTRA REGULACIÓN CONSTITUCIONAL SO- BRE TUTELA JURISDICCIONAL EFECTIVA}

La voz tutela jurisdiccional efectiva (TJE) proviene o se ha introducido en los países latinoamericanos a propósito de la terminología utilizada por la Constitución Española de 1978, que expresamente en su artículo 24 consagra a nivel constitucional "la tutela efectiva de derechos e intereses legítimos". ${ }^{25}$ A nivel del derecho chileno, es posible evidenciar un contenido difuso de este concepto, pero es posible encontrar algunos trabajos de sistematización, aunque aún incipientes. Esta más o menos establecido que ese es el estado del arte. ${ }^{26}$ Sin embargo, es posible afirmar, que existen lugares comunes o puntos de encuentro entre las fuentes para tratar de develar el sustrato teórico.

3.1. Primer lugar común: se trata de un derecho fundamental sin reconocimiento normativo expreso

La constitucionalización de las distintas disciplinas del derecho alcanzó obviamente también al derecho procesal y sus institutos. ${ }^{27}$ En la doctrina constitucionalista y procesal chilena no hay ninguna duda, y por ello decimos que un primer lugar común es que se trata de una voz representativa de consagración iusfundamental. Así por ejemplo Aldunate advierte que el inciso primero del artículo 19 en su numeral tercero consagra el "deber de tutela judicial" 28 tanto para derechos (subjetivos privados debemos entender) como para también los otros derechos fundamentales consagrados en la carta de 1980.

\footnotetext{
${ }^{25}$ Bordalí, Andrés, "Análisis crítico de la jurisprudencia del Tribunal Constitucional sobre el derecho a la Tutela Judicial”, Revista Chilena de Derecho, 2011, N ³8-2, pp. 311 - 337.

${ }^{26}$ VARgas, Macarena, El derecho a la ejecución forzada: noción e implicancias a partir de la jurisprudencia de la Corte Europea de Derechos Humanos, Ed. Universitarias de Valparaíso, Valparaíso, 2019, pp. 30-42

${ }^{27}$ PRIORI, Giovanni, "Del derecho de acción a la tutela jurisdiccional de los derechos", Ius et Veritas, 2014, $N^{\circ} 49,146-161$.

${ }^{28}$ Aldunate, Eduardo, Derechos fundamentales, Legal Publishing, Santiago de Chile, 2008, p. 205.
} 
GARCIA y CONTRERAS discurren sobre la misma idea señalando que se trata de derechos constitucionales que tienen una peculiar característica, al no estar ninguno de los dos expresamente reconocidos por la Constitución chilena. ${ }^{29}$

Andrés Bordalí, en la doctrina procesal, sostiene que "el reconocimiento de la tutela judicial en cuanto derecho fundamental requiere de un procedimiento interpretativo complejo, pues no hay precepto que lo reconozca formalmente". ${ }^{30}$

Macarena VARGAS cataloga de "exiguo"31 el reconocimiento que la Constitución Política de la República (CPR) de Chile hace de las garantías procesales en general y del derecho a la tutela judicial. A propósito de la falta de reconocimiento y la confusión que ello genera, máxime que las investigaciones de la autora referida se enderezan a buscar fundamentación para vigorizar el contenido de efectividad en cuanto ejecución de las resoluciones judiciales como parte indiscutible de la TJE.

Así las cosas, es claro, que, pese a su falta de reconocimiento expreso este binomio categorial reviste naturaleza iusfundamental y ello tiene implicancias para el rol y función de la potestad pública que la ejerce.

Supone, en una comprensión contemporánea del Estado de Derecho Constitucional y de la dogmática de mayor difusión en los países latinos, que éstos conforman un ideario de valores en cuya faceta correctiva o de ordenación de conductas, pueden proyectarse como principios o mandatos de optimización y en definitiva en la categoría de normas jurídicas. ${ }^{32}$ Normas jurídicas que no obstante al tratarse de orientaciones de conducta hacia las funciones estatales encargadas de concretarlas regladamente (legislador y juez), ha encontrado un terreno complejo en su integración, no exento de confusiones a la hora de determinar su contenido.

Pese a esta nota de atipicidad, ha recibido pleno reconocimiento por las fuentes jurisprudenciales más relevantes; los fallos del Tribunal

\footnotetext{
${ }^{29}$ García, Gonzalo; Contreras, Pablo, "El derecho a la tutela judicial y el debido proceso en la jurisprudencia del Tribunal Constitucional chileno", Estudios Constitucionales, 2013, N ${ }^{\circ} 11-2$, pp. $229-282$.

${ }^{30}$ Bordalí, Andrés, Derecho Jurisdiccional, Ediciones Universidad Austral, Valdivia, 2016, $1^{\circ}$ ed., p.185.

${ }^{31}$ VARGAS, cit. (n. 26), p. 31.

${ }^{32}$ Alexy, Robert, Teoría de los Derechos Fundamentales, trad. de Bernal, Carlos, Centro de Estudios Políticos y Constitucionales, Madrid, 2007, $2^{\circ}$ ed., pp. 67-70.
} 
Constitucional y la Corte Suprema. Así, por ejemplo, en nuestros días el TC se ha pronunciado en torno a la naturaleza iusfundamental de la TJE:

"Que, de esta forma, el derecho a la tutela judicial efectiva tiene una doble dimensión. Por una parte, adjetiva, respecto de los otros derechos e intereses, y por la otra, sustantiva, pues es en sí mismo un derecho fundamental autónomo, que tiene por finalidad que las personas accedan al proceso como medio ordinario de resolución de los conflictos jurídicos, lo que resulta un presupuesto mínimo de todo Estado de Derecho". ${ }^{33}$

En el mismo sentido, a propósito del solve et repete:

"Que, por lo demás, siguiendo esta tendencia, el legislador ha ido derogando expresamente dicho injustificado condicionamiento procesal, por no ser conciliable con un régimen de Estado de Derecho. Así, en el Mensaje que dio origen a la aludida Ley N. ${ }^{\circ} 20.087$, sobre reforma al procedimiento laboral, y en la que -entre otros aspectos- se eliminó el referido inciso tercero del artículo 474 del Código del ramo, se dejó explícita constancia de que, a este respecto, su objetivo fue "materializar en el ámbito laboral el derecho a la tutela judicial efectiva, que supone no sólo el acceso a la jurisdicción sino también que la justicia proporcionada sea eficaz y oportuna" (Boletín 3.367-13, Mensaje Presidencial, septiembre de 2003, p. 4)". ${ }^{34}$

Pero no sólo el TC chileno se ha pronunciado en fallos recientes sobre su carácter iusfundamental, también lo ha hecho la Corte Suprema, independiente de su contenido, que veremos encuentra cierta sistematización por la doctrina chilena.

El máximo tribunal chileno ha dicho recientemente:

"Que uno de los intereses que deben ser protegidos y útil a la resolución que debe ser adoptada, dice relación con el derecho de las personas a acceder libremente a un tribunal de justicia para la protección de sus derechos, también conocido en la doctrina moderna como derecho a la tutela judicial efectiva, asegurado por el N. ${ }^{\circ} 3$ del artículo 19 de la Constitución Política de la República, pues, aunque no esté designado expresamente en su texto escrito, carecería de sentido que la Carta Fundamental se hubiese esmerado en asegurar la igual protección de la ley en el ejercicio de los derechos, como la prerrogativa a la defensa jurídica, a ser juzgado por el juez natural, a un justo y racional procedimiento, si no partiera de la base de la existencia

\footnotetext{
${ }^{33}$ Tribunal Constitucional, 9 de julio de 2020, Rol 8.452/20.

${ }^{34}$ Tribunal Constitucional, 25 de junio de 2020, Rol 7.587/19.
} 
de un derecho anterior a todos los demás y que es presupuesto básico para su vigencia, esto es, el derecho de toda persona a ser juzgada, a presentarse ante el juez, a ocurrir al magistrado, sin estorbos o condiciones que se lo dificulten, retarden o impidan arbitraria o ilegítimamente".

"En el actual estado de desarrollo del derecho nacional e interpretando la garantía constitucional de acceso a la justicia con un criterio finalista, amplio y garantista, cualquier limitación por vía de interpretación que obste al derecho a la tutela judicial, aparece despojada de la razonabilidad y justificación que precisaría para ser aceptada como admisible a la luz de lo dispuesto en el N. ${ }^{\circ} 26$ del artículo 19 de la Carta Fundamental". ${ }^{35}$

Es manifiesta la concepción en un fallo aún más reciente:

"Que tal error configura sin duda una falta grave, desde que impide el acceso al sistema judicial, teniendo en consideración el derecho de las personas a acceder libremente a un tribunal de justicia para la protección de sus derechos. Tal basamento, que la doctrina denomina como derecho a la tutela judicial efectiva, se constituye como fundamento esencial de todo Estado de Derecho, y se encuentra garantizado mediante el numeral $3^{\circ}$ del artículo 19 de la Constitución Política de la República, al consagrar la prerrogativa universal de igual protección de la ley, el derecho a la defensa jurídica, el derecho a ser juzgado por el juez natural, y el derecho a un justo y racional procedimiento, garantía que, además, encuentra como contrapartida orgánica, los principios rectores de la actividad jurisdiccional consagrados en el artículo 76 del texto constitucional, en especial el de inexcusabilidad, que impone a los jueces el deber imperativo de otorgar un pronunciamiento de mérito sobre la controversia que legalmente se le plantee, sin poder excusarse de hacerlo". ${ }^{36}$

No cabe duda, de acuerdo a estas breves pero contundentes manifestaciones jurisprudenciales, que estamos frente a un derecho fundamental en el ordenamiento chileno. Ahora, merece atención lo postulado por MARINONI en torno a darle una nota diferenciadora. El profesor brasileño postula que estamos frente a un derecho de naturaleza prestacional. El derecho fundamental a la prestación jurisdiccional efectiva fue proclamado como el mas más importante de los derechos, exactamente por constituir

\footnotetext{
${ }^{35}$ Corte Suprema, 3 de julio de 2018, Rol 5098-2017.

${ }^{36}$ Corte Suprema, 3 de enero de 2020, Rol 29.767-2019.
} 
el derecho a hacer valer los propios derechos. ${ }^{37}$ Aparece la importancia de estar elevados a esta categoría y superada o escindida de la idea de garantía, que clásicamente supone un medio de defensa frente a la actividad estatal. El concepto iusfundamental importa más que eso. Por cierto, que incorpora la omisión de agresiones, pero sobre todo denota actividad de promoción, respeto y protección del Estado respecto de estos derechos. ${ }^{38}$

\subsection{Segundo lugar común: necesidad de precisiones conceptuales}

La Constitución chilena de 1980, regula en su artículo 19 numeral tercero, lo que la doctrina y jurisprudencia chilena han categorizado a través de varias de las denominaciones acceso a la justicia, debido proceso y tutela judicial. El segundo lugar común que es posible pesquisar, es que se escogió un tratamiento difuso en cuanto norma, pues no se utilizaron las expresiones tutela jurisdiccional, ni efectividad, ni debido proceso, ni proceso justo, tampoco derecho a la acción ni acceso a la justicia.

Desde ya despejemos: TJE no es sinónimo de debido proceso ni del derecho de acción. Coinciden estudios sobre la jurisprudencia chilena ${ }^{39}$ al respecto, en relación con que se trata de categorías distintas y que la CPR lo que hizo fue regular un breve e insuficiente catálogo de garantías en los numerales del Art. 19. En este sentido, Bordalí y VARGAS, coinciden en que deben separarse desde luego los conceptos de debido proceso y TJE conforme la norma constitucional, así como el derecho fundamental de acceso a la justicia o derecho de acción. Es posible sin embargo encontrarlos o situarlos dentro de la precaria regulación. ${ }^{40}$ En tanto el inciso primero del Art. 19 se encarga de asegurar a todos los ciudadanos "la igual protección en el ejercicio de sus derechos". En el caso del debido proceso o proceso justo, este conjunto de garantías de origen anglosajón ${ }^{41}$ encontraría a su vez recogimiento en la expresión "racional y justo procedimiento" consagrada

\footnotetext{
${ }^{37}$ MarinONI, cit. (n. 11), RB-8.1

${ }^{38}$ De Oliveira, Carlos Alberto, "El derecho a la tutela jurisdiccional efectiva desde la perspectiva de los derechos fundamentales", Revista de Derecho U. Austral de Chile, 2009, Vol. XXII, N ${ }^{\circ}$, pp. 185-201.

${ }^{39}$ Bordalí, cit. (n. 25), y García; Contreras, cit. (n. 29).

${ }^{40}$ Bordalí, cit. (n. 25), y García; Contreras, cit. (n. 29).

${ }^{41}$ Alvarado, Adolfo, Lecciones de Derecho Procesal Civil, Editorial Juris, Rosario, 2009, p. 177.
} 
en el inciso sexto de la cláusula en comento ${ }^{42}$ que al efecto prescribe:

"Toda sentencia de un órgano que ejerza jurisdicción debe fundarse en un proceso previo legalmente tramitado. Corresponderá al legislador establecer siempre las garantías de un procedimiento y una investigación racionales y justos."

Los incisos primero y sexto, pese a servir de referencia para la interpretación, son regulaciones difusas que, no obstante, permiten por la integración jurisprudencial y la aplicación de los tratados internacionales ratificados y vigentes en Chile conforme el Art. 5 inc. $2^{\circ}$ de la CPR, ser consideradas como norma jurídica vigente y reconocida en nuestro ordenamiento. Destacamos particularmente en este último apartado, la Declaración Universal de Derechos Humanos de 1948, La Convención Americana de Derechos Humanos de 1969 y el Pacto de Derechos Civiles y Políticos de 1976.

BORDALí, sistematizando y criticando las descripciones de la jurisprudencia constitucional chilena, postula que el artículo 19 numeral tercero comprende cinco derechos: la tutela judicial (del inciso primero), la defensa jurídica y su gratuidad (del inciso segundo y tercero), el derecho a un juez natural (inciso cuarto) y por último "el derecho a un debido proceso". ${ }^{43}$

Categoriza en este sentido el profesor valdiviano a la TJE como un derecho más amplio o meta derecho donde cabrían los demás, separándolo a su vez del derecho de acción o de acceso a la justicia que sería el punto de inicio, la puerta de entrada a la tutela jurisdiccional, que solo "asegura al justiciable la realización de los actos de apertura y sustanciación del proceso". ${ }^{44}$ Advierte, además, que no es necesario traer calificativos como el de efectividad pues aquello es propio del derecho español, e implica importar toda la problemática interpretativa que ha generado esta expresión en la jurisprudencia hispana. ${ }^{45}$

No concuerdo con la categorización ni con este último comentario. Si bien es cierto, que se trata de instituciones diversas, la TJE atendido su nota realista y deóntica, está fuertemente concentrada en la parcela que le corresponde a la materialización tempestiva, justa y proporcional de

\footnotetext{
${ }^{42}$ Bordalí, cit. (n. 25), pp. 311-337.

${ }^{43}$ Bordalí, cit. (n. 25), p. 316.

${ }^{44}$ Bordalí, cit. (n. 25), p. 316.

${ }^{45}$ Bordalí, cit. (n. 25), p. 311-337.
} 
los derechos afirmados por quienes reclaman su intervención. Prueba de ello es la contemporánea incorporación del derecho a la ejecución de las resoluciones como parte de su contenido. ${ }^{46} \mathrm{El}$ debido proceso en tanto, dado su origen anglosajón, se construye como un sistema de garantías contra el Estado que dispone de la utilización exclusiva del instrumento procesal para resolver conflictos o proteger derechos. Esto no es baladí, pues como hemos referido, hay una diferencia entre la concepción derecho y garantía ${ }^{47}$ en que el primero de ellos, evoca para estos efectos particulares analizados, el sentido de prestación estatal más que un elemento de defensa únicamente respecto del abuso y la arbitrariedad en el ejercicio del poder.

De otro lado, en cuanto a la importación de la expresión efectividad, ésta ha sido reconocida no sólo por el derecho hispano, sino que es una expresión que cruza toda cultura contemporánea continental y prueba de ello es que en la doctrina italiana de autoridad se ha dicho: "la tutela jurisdiccional o es efectiva o no es". ${ }^{48}$ Por ende, sea que le otorguemos nosotros el calificativo o no, su naturaleza necesariamente axiológica es difícil de resistir.

Compartimos eso sí, las conclusiones a las que arriba Macarena VARGas al intentar conceptualizar estos institutos complejos. Nos parece que recoge, dentro de la germinal doctrina chilena sobre el punto, (eso sí en clave negativa) una sencilla y eficaz forma de escindir institutos. "El derecho a la tutela judicial es un derecho fundamental que asiste a todos los ciudadanos. No es sinónimo de acceso a la justicia en tanto actos de apertura e inicio del proceso ni de asistencia jurídica gratuita. Tampoco es sinónimo de debido proceso entendido como el conjunto de estándares mínimos que regulan el desarrollo de un proceso de acuerdo a criterios de razonabilidad y justicia". ${ }^{49}$

Finalmente, García y Contreras se aventuran con una definición en sentido positivo. La TJE "importa el reconocimiento de un derecho prestacional que recaba del Estado la protección jurídica debida, en el igual ejercicio de los derechos ante la justicia, proscribiendo la autotutela, y

\footnotetext{
${ }^{46}$ VARGAS, cit. (n. 26), p. 59.

${ }^{47}$ Aldunate, cit. (n. 28), p. 79.

${ }^{48}$ Proto, Andrea, La tutela jurisdiccional, trad. de Priori, Giovanni, Palestra, Lima, 2014, , $1^{\circ}$ ed., p. 12.

${ }^{49}$ VARGAS, cit. (n. 26), p. 59.
} 
garantizando una respuesta a la pretensión de derechos e intereses legítimos con autoridad de cosa juzgada y con la eficacia coactiva que demanda la satisfacción de derechos fundamentales". ${ }^{50}$

IV. LA POROSIDAD DE LA REGULACIÓN CONSTITUCIONAL ACTUAL: LA NECESIDAD DE RELEER SU CONTENIDO

Teniendo presente que, en el derecho chileno, medianamente esclarecido está que debido proceso, derecho a la acción y TJE son cuestiones diferentes, en lo que respecta a este trabajo, es importante preguntarse por el contenido hasta el momento develado para conocer si dentro de él puede asignarse algún espacio a algo más, especialmente en reconocidos tiempos de crisis por la inefectividad de la justicia.

En este sentido, la garantía del juez natural, el derecho a la defensa, a un juez imparcial, a la motivación de la sentencia, a la impugnación de las resoluciones judiciales, entre otras, forman parte del conjunto de garantías del proceso justo, ${ }^{51}$ que es una categoría que juega una directa relación con la finalidad y función de la TJE, pero que no se identifica con ella, sino con los estándares conforme a los cuales debe sustanciarse el instrumento de su desenvolvimiento: el proceso judicial.

¿Cuál es el contenido entonces de este derecho fundamental a la TJE y porqué nos interesa releerlo?

De momento, digamos que hay pronunciamientos desde la doctrina comparada y también en Chile. En este sentido, está el derecho chileno un poco atrás en cuanto al reconocimiento de la integridad de su contenido, especialmente en aquello que dice relación con la pretensión correctiva del calificativo efectividad.

\subsection{Las ventajas de la porosidad}

Independiente de si estemos en la posición de considerar, especialmente al Art. 19 numeral $1^{\circ}$ de la CPR como una regla o un principio, la expresión textura abierta desarrollada por HART es muy reveladora de la situación que

\footnotetext{
${ }^{50}$ García; Contreras, cit. (n. 29), p. 244.

${ }^{51}$ Navarro, Enrique, "El Debido Proceso en la Jurisprudencia del Tribunal Constitucional”, Anuario de Derecho Constitucional Latinoamericano, 2013, $\mathrm{N}^{\circ} 19$, pp. 121-145.
} 
se quiere plantear. ${ }^{52}$ El problema del lenguaje en la utilización de la técnica regulatoria es una cuestión pasada, actual y futura. El profesor oxoniense describió muy bien la idea señalando que "somos hombres no dioses" 53 por ende es imposible que de antemano puedan establecerse pautas de conducta generales que logren llegar a solucionar y prever todos los casos y situaciones.

"Es una característica de la condición humana (y por ello también condición de los legisladores) que en todos los casos en que tratamos de regular en forma no ambigua y por adelantado, alguna esfera de conducta por medio de criterios o pautas generales, para ser utilizados sin nuevas directivas oficiales en ocasiones particulares, nuestro empeño halla dos obstáculos conectados entre sí. El primero es nuestra relativa ignorancia de los hechos; el segundo nuestra relativa indeterminación de propósitos". ${ }^{54}$

El diagnóstico de HART no puede ser más certero y es precisamente la pretensión de certeza y formalismo absoluto lo que lleva al iluso "paraíso de conceptos jurídicos". ${ }^{55}$ En efecto, debe reconocerse que, a propósito de pautas de conducta de la mayor generalidad como lo es una norma iusfundamental para la administración de justicia, no puede pensarse únicamente con un sentido y para todos los casos de manera uniforme. Si bien es cierto la Constitución chilena fue precaria en la regulación, y preferiríamos una mayor definición de intenciones, se agradece al momento de interpretar (o argumentar) el contenido de un derecho fundamental, la ductilidad como un elemento disponible para ello. ${ }^{56}$ Esto permite que problemas o propósitos no tenidos a la vista al momento de positivar puedan irse incorporando conforme la evolución y el dinamismo de la realidad jurídica y social.

Estoy por esta flexibilidad y/o ductilidad como propone ZALGREBELSKY ${ }^{57}$ ante la indeterminación. Visto desde una perspectiva más general, por entender que la TJE en tanto derecho fundamental forma parte de la

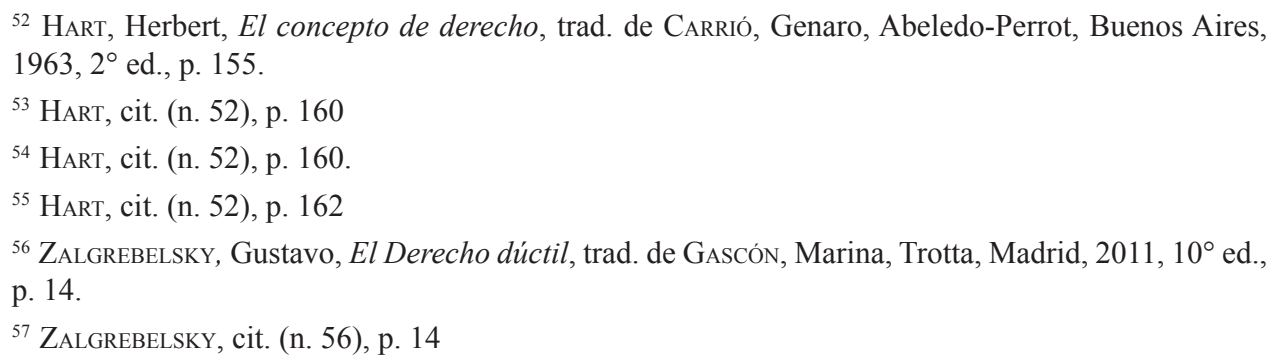


"porosidad" del sistema jurídico, ${ }^{58}$ si es que alguno hay en Chile.

Esta apertura y dinamismo permite integrar no solo normas en las respuestas que debe dar el sistema, sino también y sobre todo principios y valores. Si nos detenemos acá, logramos traer esa juridicidad indisponible o contenido mínimo, como primera cuestión, y consecuentemente el fácil reconocimiento por parte de la unidad porosa de los derechos fundamentales y sus mutaciones estacionarias.

Finalmente, este sistema dúctil es más accesible para la cultura jurídica continental propia de los ordenamientos jurídicos latinoamericanos, en pro de instaurar el EDC. Lo anterior por dos razones: necesita el juzgador en la integración de los valores y principios de argumentación, de la razón para la justificación de la decisión, en un intento por superar la búsqueda permanente de voluntades de la autoridad. Y, además, permite tener como directriz al componente axiológico ético o moral, que forma parte u orienta basalmente al derecho, y que puede venir representado como bien común, interés público o el nombre que quiera dársele.

En concreto, en las Actas Oficiales de la CPR de 1980 no hay constancia siquiera que se haya abordado el tema relativo a la efectividad de la tutela judicial, sino más bien se englobó todo dentro del concepto de debido proceso legal. En este sentido se decidió voluntariamente, cuestión que podemos extender hasta hoy, que la consagración a nivel constitucional debía ser flexible o porosa. Así, en la sesión n ${ }^{\circ} 101,{ }^{59}$ Ortúzar, presidente de la Comisión de Estudios de la Nueva Constitución, señalaba que el concepto "ya está incorporado a la doctrina jurídica universal y, en segundo lugar, es un concepto cuyas precisiones pueden ir evolucionando de acuerdo con el tiempo y ser recogidas y precisadas por la jurisprudencia" como de hecho ha ocurrido. En consecuencia, se le considera como un concepto flexible, que va modificándose conforme a la evolución institucional, política y social de un país.

Con lo dicho, debemos plantear que la realidad social y política del país exige una relectura de la integración de este derecho fundamental.

\footnotetext{
${ }^{58}$ García Amado, Juan Antonio, “Teorías del sistema jurídico y concepto de derecho”, Anuario de Filosofía del Derecho, 1985, No2, pp. 225-236.

59 Biblioteca del Congreso Nacional, "Actas Oficiales de la Comisión de Estudios de la Nueva Constitución Política de la República”, Sesión 101º 30 de diciembre de 1974, T. III., https://www. bcn.cl/historiadelaley/historias-de-la-ley-de-la-constitucion/, consultada el 5 de junio de 2021.
} 
Ello ya se ha hecho y nadie ha rajado vestiduras. Primero siquiera existía la idea de TJE en la CPR chilena. Luego, el concepto fue integrándose no exento de confusiones y la doctrina y jurisprudencia han hecho un esfuerzo para delimitarlo y contornearlo. Hoy no hay duda de que es un concepto separado de las garantías del proceso justo y que tiene un contenido diverso, pero esencialmente prestacional. Sin embargo, la cuestión no termina ahí, el objeto de nuestro análisis es el inciso primero del Art. 19 de la CPR, en cuanto derecho fundamental, lo que se ha dicho sobre él en forma aislada y lo que se ha ido proponiendo para adecuarse a los tiempos que corren, dadas sus características porosas o abiertas.

\subsection{La integración progresiva de contenido}

Aprovechando esta textura abierta declarada de la consagración precaria que la CPR de 1980 detenta en cuanto a TJE, veamos básicamente que es lo que se ha recogido en tanto base jurisprudencial y doctrinal. Es relevante en este sentido señalar que la mayoría (sino todos) de los pocos autores chilenos que se han referido a la materia se pronuncian en torno a la jurisprudencia del TC chileno. Sin embargo, es de destacar que hay coincidencias $^{60}$ y desencuentros. Enunciaré algunos puntos de encuentro que sirven para elaborar un catálogo que va dándole sustrato al instituto.

En primer lugar, se trata de normas que imponen un "mandato al legislador"61 para su regulación. Por ende, la técnica legislativa influirá directamente sobre la concreción de la TJE, cuestión importante de cara a lo que pretendemos develar finalmente, pues esta idea implica que se reconozcan distintas naturalezas en los requerimientos de tutela, por ende, el diseño procesal, ahora en clave de derechos fundamentales, debe tender a la máxima realización posible del derecho en análisis. Agreguemos sí, que la tutela jurisdiccional como señala Aldunate, es un derecho prestacional en Chile tanto para la tutela de derechos constitucionales como para los de valor infra constitucional, ${ }^{62}$ parece obvio, pero es mejor explicitarlo.

\footnotetext{
${ }^{60}$ Entre quienes coinciden medularmente podemos encontrar a Andrés Bordalí, los profesores Gonzalo García y Pablo Contreras, Macarena Vargas y el profesor Enrique Navarro.

${ }^{61}$ García; Contreras, cit. (n. 29), p. 240.

${ }^{62}$ Aldunate, cit. (n. 28), p. 205.
} 
Ensegundolugar,setratade"garantíasadaptadasalosprocedimientos". ${ }^{63}$ GARCía y Contreras no lo dicen expresamente por su cercanía al Derecho Constitucional más que al Derecho Procesal, pero lo que plantean es una idea trabajada en la dogmática procesal y que queremos incorporar: la TJE tiene un elemento común hoy y es que se reconozcan las características particulares de los derechos que se pretenden tutelar. Deben reconocerse y tratarse las diferencias que son manifiestas en la realidad material y que ya ha venido haciendo el derecho sustancial desde hace mucho tiempo. Es más explícito en este sentido NAVARRO, que trata a esta característica común al debido proceso y a la TJE señalando que "las garantías dependen de la naturaleza del asunto". ${ }^{64}$ Un ejemplo palmario es el proceso del trabajo, que reconoce y absorbe instrumentalmente principios propios de las normas laborales materiales a efectos de corregir las evidentes condiciones de desigualdad de las partes en este tipo de relaciones contractuales.

En tercer lugar, en cuanto a su contenido esencial, es posible distinguir que los autores coinciden en cuanto las siguientes manifestaciones:

Derecho de acceso a la justicia y derecho de acción

Resolver las pretensiones conforme derecho.

Derecho a una sentencia motivada y fundada

Derecho a la duración racional del proceso judicial o sin dilaciones indebidas.

Derecho a la irrevocabilidad de la decisión jurisdiccional o cosa juzgada.

Derecho a la ejecución de las resoluciones judiciales.

El contenido pareciera muy prístino, sin embargo, de lo que menos se habla en nuestro medio es de la parte más concreta de su contenido, de la parte de este núcleo esencial que forma parte de la efectividad, de la realización de los derechos materiales, de la función jurisdiccional propiamente dicha. Es decir, del escaso reconocimiento que se da a "la efectividad de las resoluciones judiciales". ${ }^{65}$

Si bien es cierto se han reconocido al menos las categorías de la ejecución y la razonabilidad del uso del tiempo como hemos señalado, éstas son las que denotan menos desarrollo.

\footnotetext{
${ }^{63}$ García; Contreras, cit. (n. 29), p. 243.

${ }^{64}$ NaVArro, cit. (n. 51), pp. 136.

${ }^{65}$ Bordalí, cit. (n. 25), p. 133.
} 
VARGAS, es categórica al señalar que se trata de un derecho fundamental que va más allá de la declaración de mérito, pues con ella no se acaba el ejercicio jurisdiccional. ${ }^{66} \mathrm{El}$ abandono de la ciencia procesal chilena a estas cuestiones a contrario del desarrollo de la actividad cognitiva de los jueces es sin duda un factor para la no consideración de la efectividad en el estudio del derecho fundamental a la tutela judicial. Veamos entonces, si hay esperanza en los "nuevos vientos en la doctrina y jurisprudencia nacional". ${ }^{67}$

\section{LA IDONEIDAD PROCESAL: DE LA TUTELA CAUTELAR A LAS TUTELAS DIFERENCIADAS}

\subsection{El punto de inicio de las otras formas: la tutela cautelar}

Dentro de la expresión efectividad a propósito del análisis del contenido nuevo o reciente que podamos ir integrando, Bordalí nos dice se pueden categorizar tanto la ejecución como la actividad, tutela o protección por vía cautelar. ${ }^{68}$ En el mismo sentido, PrIORI en Perú ha postulado expresamente a la efectividad como una garantía que comprende no solo la ejecución sino también la cautela a efectos del cumplimiento de las resoluciones judiciales. ${ }^{69}$

Sin duda, investigaciones desarrolladas entre nosotros, como la de VARGAS (que hemos citado ya) y SiLVA, ${ }^{70}$ van concretando definitivamente la idea de que la ejecución en tanto momento, proceso autónomo o actividad jurisdiccional, debe quedar consagrado como parte del contenido indiscutible de la TJE.

Sin embargo, sobre la que no hay consenso es en relación con el derecho a la actividad cautelar. Esto es relevante porque la cautela es un punto de partida para el reconocimiento de "otras formas de tutela jurisdiccional"71 distintas a la cognitiva y a la ejecutiva. Estas otras formas desmitifican la

\footnotetext{
${ }^{66}$ VARGAS, cit. (n. 26), p. 9.

${ }^{67}$ VARGAS, cit. (n. 26), p. 39.

${ }^{68}$ Bordalí, cit. (n. 25), p. 133.

${ }^{69}$ Priori, Giovanni, El proceso y la tutela de los derechos, Fondo Editorial, Lima, 2019, $1^{\circ}$ ed., p. 77.

${ }^{70}$ Nos referimos en especial a la obra La transparencia patrimonial del deudor en la ejecución civil, Thomson Reuters, Santiago de Chile, 2014.

${ }^{71}$ PrIORI, cit. (n. 69), p. 144.
} 
idea de una única vía y el reconocimiento de la flexibilidad necesaria para adecuar las necesidades sociales al tiempo procesal.

El punto no es menor, pues lo cierto es que la tutela cautelar es la primaria y más elemental categoría dentro del derecho procesal que reconoce lo concreto de un proceso y la necesidad de adecuación de la técnica procesal que debe existir en toda prestación de tutela judicial. ${ }^{72}$ Sobre ella se ha construido el debate para discutir en torno a que las formas de tutela provisional de los derechos ${ }^{73}$ pueden resolver el eterno problema del tiempo y la eficiencia.

En este sentido, reconoce y propone la consagración de la tutela cautelar dentro de la TJE BORDALÍ al señalar: "el valor que debe ser atribuida a la tutela cautelar, debe entenderse en la necesidad de las partes de un proceso judicial que ampare a los derechos e intereses esgrimidos de una manera efectiva y en sus propios términos". ${ }^{74}$ El autor esgrime jurisprudencia de la Corte Constitucional italiana en base a la cual se ha afirmado que la tutela cautelar constituye un componente esencial del derecho a la tutela judicial y de cómo esta sentencia (reconducida por la doctrina italiana) es el reconocimiento de la flexibilidad y adaptación tutelar judicial a las necesidades de entregar respuesta pronta y efectiva según el tipo de derechos de que se trate. ${ }^{75}$ Algo que ya hemos venido adelantando, independiente de si se le catalogue como cautelar o no, la necesidad de flexibilizar la tutela judicial para que ésta sea o pueda ser efectiva. Para ello el basamento es reconocer la existencia de diferencias y en que la uniformidad de la técnica procesal para todo tipo de pretensiones, estilo juicio ordinario, es un mito, como denunció hace más de una década MARINONI. ${ }^{76}$

PiCó Y JunOY, en España aboga también por la inclusión de estas otras técnicas diversas enfocadas en la efectividad. "La efectividad de la tutela judicial, a pesar de ser un asunto debatido y controversial en sí mismo, hace relación al acatamiento y cumplimiento de la resolución judicial: que ella sea capaz de producir un cambio en la vida cotidiana de las personas o, en otras palabras, que la jurisdicción logre, realmente, tutelar y reestablecer

\footnotetext{
${ }^{72}$ MarinOni, cit. (n. 11), RB-5.2.

${ }^{73}$ Cortez, Gonzalo, La tutela cautelar en el proceso civil, Thomson Reuters, 2016, $1^{\circ}$ ed., p. 5.

74 Bordalí, cit. (n. 25), p. 133.

75 Bordalí, cit. (n. 25), p. 133.

${ }^{76}$ MARINONI, cit. (n. 11), RB-3.1.
} 
el derecho inobservado. Así, el principio de efectividad (que se manifiesta, incluso, en el nombre de la tutela judicial, al ser esta "efectiva") se concretaría en tres grandes garantías: la inmodificabilidad de las resoluciones judiciales, la potestad cautelar del juez (medidas cautelares), y, especialmente, en la ejecución -incluso compulsivamente- de la resolución judicial firme". ${ }^{77}$

De los trabajos chilenos que han abordado el problema, quienes se oponen, al menos formalmente, a reconocer la tutela cautelar como parte del núcleo central, son Gonzalo García y Pablo Contreras señalando como argumento único que si la tutela cautelar constituyera parte del contenido esencial del derecho a la tutela judicial efectiva "debería concurrir siempre en todo procedimiento, cuestión que no acontece puesto que depende de circunstancias contingentes propias de la naturaleza de la pretensión. Existen determinados presupuestos jurídicos para la adopción de una medida cautelar: el fumus boni iuris (apariencia del buen derecho), el periculum in mora (el peligro en la demora), la adecuación, la no irreversibilidad y la proporcionalidad. La concurrencia de la apariencia de un buen derecho "no responde a que la pretensión sea probablemente estimada (juicio subjetivo), sino a que la misma pueda serlo (juicio objetivo). La medida cautelar, por otro lado, requiere que exista un real, efectivo y grave peligro que su no disposición derive en consecuencias irreparables". ${ }^{78}$

Resisto el planteamiento de los profesores García y ConTreras por las breves razones que paso a explicar:

En primer término, el argumento es que para que las medidas cautelares se den en un proceso determinado deben cumplirse una serie de presupuestos que no se dan en todos los casos. Esta es una confusión entre potencia y acto como apunta MonRoy ${ }^{79}$ usando la clásica diferenciación aristotélica. Antes de la existencia del proceso (potencia), y para el evento de que sea necesario en lo concreto (acto) existe un derecho prestacional a la protección judicial que se compone de una serie de subderechos ya referidos, dentro de los cuales recientemente se ha reconocido (al menos por la doctrina) a la ejecución y creemos también debiera reconocerse la eventual protección cautelar o provisional a través de sus distintas nomenclaturas. Obviamente, puestos en

\footnotetext{
${ }^{77}$ Picó I Junoy, Joan, Las garantías constitucionales del proceso, Bosch, Barcelona, 2011, $2^{\circ}$ edición, p. 85 .

${ }^{78}$ García; Contreras, cit. (n. 20), p. 252.

${ }^{79}$ Monroy, Introducción al proceso civil, Temis, Bogotá, 1996, T.I, p. 245.
} 
el caso concreto, si no es necesaria o no se dan los supuestos que permiten la concesión de la tutela provisional, cautelar, anticipatoria, de urgencia o como se le quiera titular a esta serie de nuevas tutelas jurisdiccionales, este derecho no podrá darse en la especie, del mismo modo que si no me encuentro en la posición jurídica de dueño, el tribunal no podrá proteger mi derecho de dominio en un juicio declarativo pues nunca fui titular del mismo. Toda institución procesal tiene supuestos de concreción, pero eso no quita que, en tanto eventualidad, debe existir la posibilidad y disponibilidad de mecanismos adecuados o idóneos para cumplir el estándar de efectividad.

Como señala RosATTI, "el derecho a la jurisdicción antes del proceso es el derecho a exigir del Estado -monopolizador del servicio de administración de justicia - el cumplimiento de los presupuestos jurídicos y fácticos necesarios para satisfacer el cometido jurisdiccional ante la eventualidad de una litis concreta". 80

El segundo argumento, es que los autores mencionados citan dos fallos ${ }^{81}$ que muestran indirectamente supuestos de pronunciamientos sobre tutela cautelar. Desde ya digamos que en realidad versan sobre formas que puede adoptar la tutela provisional como la anticipación o la conservación del status quo, más que sobre cautela en estricto sensu, y en ambos el razonamiento no es por el rechazo a la posibilidad de que forme parte esta modalidad tutelar, sino que en realidad reconocen la existencia de la misma y la confrontan con otros derechos materiales infra constitucionales. Por ejemplo, de técnica anticipatoria ${ }^{82}$ en pro de la protección de derechos subjetivos cuya afectación requería de un pronunciamiento acelerado. Por otro lado, se comenta un fallo en que se concluye la superposición de la tutela de urgencia por encima de la bilateralidad de la audiencia, que sin dudas forma parte del núcleo esencial del debido proceso. ¿Cómo es posible que el TC haya justificado por encima de una garantía del debido proceso a una decisión mediante tutela o técnica de urgencia sin que ésta última forme parte de algo de tal entidad que permita hacerlo ceder? Porque como se ha dicho,

${ }^{80}$ Rossatti, Horacio, El derecho a la jurisdicción antes del proceso, Depalma, Buenos Aires, 1984, p. 47.

${ }^{81}$ Ambas sentencias del Tribunal Constitucional: Rol 349-04, considerando 37 ${ }^{\circ}$ del 22 de marzo de 2013, Rol 2.411-13, considerando $6^{\circ}$.

${ }^{82}$ Pozo, Felipe, La Tutela jurisdiccional anticipada en el proceso civil, Editorial Jurídica de Chile, 2013, p. 63. 
se reconoce indirectamente que existen otras formas de tutela jurisdiccional al derecho material a proteger. Existen y son parte de la necesidad de cada caso concreto, cumpliéndose los presupuestos de concesión. Su punto de confluencia o inicio fue el instituto cautelar, expandiéndose hacia la tutela cautelar innominada, ${ }^{83}$ porque judicialmente, todo lo extraño a las dos modalidades típicas de tutela (declarativa y ejecutiva) se tiende a catalogar entre nosotros como de naturaleza cautelar. Esta impropiedad ha sido recogida por la doctrina chilena a propósito de la acción de protección (en realidad procedimiento declarativo sumarial de protección de derechos fundamentales) pero no por el lenguaje jurisprudencial que insiste tozudamente en el equívoco de considerarla una acción cautelar. ${ }^{84}$

Estamos sin duda por la incorporación en el contenido de la TJE de estas nuevas técnicas en cuanto idóneas y/o adecuadas o en sus diversas formas, en tanto permitan realizar la efectiva prestación del derecho fundamental en análisis. Diferente es, por cierto, de aquélla que escapa al patrón tradicional, de lo cognitivo y ejecutivo, como parte si se quiere, de la tutela cautelar, de la tutela provisional, de urgencia o simplemente de la necesaria idoneidad o adecuación que la prestación jurisdiccional requiere a cambio de poder realizar la justicia, más que arrojar una solución inocua e intempestiva, pero legal. ${ }^{85}$

\subsection{La relación entre técnica procesal y efectividad}

La técnica procesal es una variante específica para la disciplina de la ciencia procesal de la técnica jurídica en general, que permite ir transformando las directivas de política jurídica en reglas claras (agregamos nosotros también principios), es decir materializando las fuentes materiales del derecho en fuentes formales. ${ }^{86}$

En sentido procesal, fue definida por PODETTI para el proceso civil como "el conjunto de procedimientos idóneos para su realización, desde la

\footnotetext{
${ }^{83}$ Marinoni, cit. (n. 11), RB. 4.2.

${ }^{84}$ Cortez, cit. (n. 73), p. 15.

${ }^{85}$ RossatTi, cit. (n. 80), p. 43.

${ }^{86}$ Hertel, Daniel, "Técnica processual e tutela jurisdicional: a instrumentalidade substancial das formas", Tesis de Magíster, Faculdade de Direito de Vitoria, Vitoria, publicada, 2004, p. 60. http://191.252.194.60:8080/handle/fdv/38, consultada el 4 de junio de 2021.
} 
elaboración y formulación de la norma, hasta la interpretación de las normas procesales y jurídicas en general, y de los hechos probados, dentro de la sentencia". ${ }^{87}$

En este sentido, no debe confundirse el tecnicismo o formalismo procesal con la técnica procesal. El primero de ellos, es una hipérbole, una atrofia de las formas que en sí mismas terminan considerándose un fin, obstaculizando la realización de los fines del proceso. ${ }^{88}$ Muy por el contrario, la técnica puede contribuir, y es factor determinante para la efectividad de la tutela jurisdiccional cuando se pone al servicio funcional de los fines del proceso. ${ }^{89}$

Clásicamente se ha entendido en sentido amplio que la técnica procesal debe ser analizada desde tres visiones: "desde la técnica adecuada para la formulación de las leyes procesales, para enseñar derecho procesal y para interpretar la ley en la sentencia o para la sentencia"..$^{90}$

En concreto, cuando nos referimos a la necesidad de adecuación de la técnica, como parte fundamental para la realización de la TJE, nos referimos a la elaboración y a la interpretación (argumentación en el EDC) judicial de la norma procesal. Sin perjuicio del importantísimo rol de la enseñanza sobre la técnica, que moldea tradiciones culturales jurídicas.

MARINONI nos sitúa en primer término en la necesidad de separar técnica y tutela. En el sentido que "es necesario aclarar que la tutela del derecho no se confunde con las técnicas procesales destinadas a permitir su prestación. Hay que establecer de una vez por todas, la separación entre las tutelas prometidas por el derecho material y las técnicas procesales. La tutela resarcitoria y la sentencia condenatoria están en planos diferentes, así como son distintos todos los tipos de tutela judicial de los derechos frente a los tipos de sentencias". ${ }^{91}$

Se plantea este plano diferenciador con la sentencia porque el mismo MARINONI ha postulado que componen entre otros a la técnica procesal idónea,

\footnotetext{
${ }^{87}$ Podetti, J. Ramiro, Teoría y técnica del proceso civil, Ediar, Buenos Aires, 1963, p. 303.

${ }^{88}$ Do SAntos, José, Efectividade do processo e técnica processual, Malheiro Editores, Sao Paulo, 2010, $3^{\circ}$ ed., p. 76.

${ }^{89}$ Hertel, cit. (n. 86), p. 62

${ }^{90}$ Podetti, cit. (n. 87), p. 304.

${ }^{91}$ Marinoni, Luiz Guilherme, "Derecho a la tutela judicial de los derechos", en Priori, Giovanni, Derecho material y proceso, Palestra, Lima, 2017, p. 53.
} 
una acción adecuada al tipo de tutela que se persigue, un procedimiento no rígido o uniforme, la disponibilidad de medidas cautelares o de técnicas anticipatorias, inhibitorias, de urgencia $\mathrm{u}$ otras diferenciadas frente a las necesidades del caso concreto, sentencias adecuadas a la especificidad de los casos y medios ejecutivos idóneas que favorezcan o vayan en pro de la realización del derecho. ${ }^{92}$

La tutela jurisdiccional por su parte dice HerTel, es decir "la presentación de una solución en el plano del derecho material, puede facilitarse o alcanzarse mediante el uso de la técnica procesal. En otras palabras, es mediante la elaboración, conocimiento e interpretación que la tutela jurisdiccional puede tornarse efectiva". ${ }^{93}$

Hay en mi opinión, en realidad más que una posibilidad, una relación directa y necesaria entre la idoneidad de la técnica procesal y la tutela del derecho. Es decir, mientras más optimizada está la técnica, mayor será la intensidad de efectividad con que podremos calificar a la actuación de la jurisdicción en su función protectora.

"Entre las tutelas de los derechos y las técnicas procesales debe haber una relación de adecuación. Así, hay tutela del derecho material y derecho de acción. Quien debe tutela judicial al derecho, como respuesta al derecho de acción, es el Estado. Pero el derecho de acción, porque es el derecho a través del cual se puede ejercer la pretensión a la tutela judicial del derecho material, es el derecho a una acción adecuada, valga decir es el derecho a que, entre otras técnicas procesales, exige la sentencia capaz de permitir la tutela del derecho material". ${ }^{94}$

"No se puede pensar en tutela judicial efectiva, sin separar las distintas formas de tutela de los derechos de las técnicas procesales que deben posibilitar su prestación. Esta separación es imprescindible para probar la compatibilidad de la estructura técnico procesal con el derecho fundamental de acción". ${ }^{95}$

\footnotetext{
${ }^{92}$ Marinoni, cit. (n. 11), RB-8.8.

${ }^{93}$ Hertel, cit. (n. 87), p. 66.

${ }^{94}$ Marinoni, cit. (n. 91), p. 54.

${ }^{95}$ Marinoni, cit. (n. 91), p. 54.
} 


\subsection{La técnica procesal idónea y el principio de la igualdad}

Como corolario de las postulaciones efectuadas hay otro argumento iusfundamental que no dice relación directa con las normas constitucionales procesales sino con el tratamiento igualitario prometido por la CPR de 1980 a todos los ciudadanos y ciudadanas.

En efecto el Art. 19 numeral segundo de la carta fundamental chilena expresa:

"La constitución asegura a todas las personas:

la igualdad ante la ley. En Chile no hay persona ni grupo privilegiados. En Chile no hay esclavos y el que pise su territorio queda libre. Hombres y mujeres son iguales ante la ley.

Ni la ley ni autoridad alguna podrán establecer diferencias arbitrarias".

La consagración en una Constitución como la chilena, de marcado corte neoliberal, ${ }^{96}$ con un Estado basado en el principio de subsidiariedad, evidentemente que pretendió establecer una igualdad meramente formal. Es decir, poner al menos por vía de declaración que no pueden establecerse diferencias fuera de la razón por parte del Estado, pero no podía asegurarse más que eso en el plano material, nada de acciones positivas en pro generar igualdad material.

Sin embargo, con el desarrollo del Derecho Constitucional y particularmente con la arremetida del EDC, es imposible no repensar el contenido y significación de esta norma. Quiero decir, la igualdad que debe y está consagrada constitucionalmente debe mirarse bajo el prisma de los derechos fundamentales y de la supremacía constitucional.

Esto supone necesariamente entender que la igualdad material se consigue sólo reconociendo la diferencia entre las personas que quedan sujetos al ordenamiento jurídico. En el reconocimiento estatal de la diferencia está la igualdad concreta, pues ello implica el reconocimiento de ventajas y desventajas en los planos de la realidad material, económico, social, cultural, religioso, étnico, de género, entre tantas otras particularidades.

Con lo dicho entonces, cabe preguntarse la igualdad de trato que promete el Estado ¿cómo se concreta en el plano procesal?, ¿tratando a todos como iguales de manera absoluta? En situaciones de igualdad, venga la

${ }^{96}$ Ferrada, Juan Carlos, "La Constitución económica de 1980", Revista de Derecho Universidad Austral de Chile, 2010, Vol. 11, pp. 47-54. 
igualdad formal y absoluta pues allí obviamente el principio tiene aplicación abstracta. ¿Y ante situaciones de desigualdad como las expresadas? En tal caso la igualdad se logra precisamente por vía el trato racionalmente desigual (o no arbitrario) que permite reconducir el desequilibrio que existe dentro y fuera de las situaciones de facto.

Esta crisis del concepto de igualdad y su necesaria integración o definición ha sido abordada por la doctrina constitucional chilena, y se ha dicho que se trata de una expresión que no puede ser considerada en forma absoluta, sino que la igualdad debe ser para los iguales y la diferencia para quienes se encuentren razonablemente en una situación de diferencia. ${ }^{97}$ Estableciéndose, por ejemplo, a propósito de la jurisprudencia del TC, cinco estándares para racionalizar la desigualdad que no solo mantienen incólume la norma constitucional, sino que, además, materializan y promueven la igualdad para con grupos desventajados o vulnerables. Entre ellos se encuentran: a) el trato diverso se justifica en la medida en que las situaciones fácticas se diferencian por cuestiones objetivas y relevantes, b) que no importe hostilidad hacia un grupo vulnerable ni se establezcan privilegios personales indebidos, c) la diferencia debe perseguir una finalidad lícita, d) adecuación y necesidad de la diferenciación para el fin perseguido y e) debe pasar un examen de proporcionalidad constitucional.

Nogueira, a propósito de las acciones positivas en promoción de la igualdad, señala que ésta es una condición general de validez de las leyes, un derecho subjetivo público de las personas y supone tratamiento diferenciado en aquellos casos en que hay diferencias jurídicas relevantes. ${ }^{98}$

Quisiera finalmente poner de relieve sólo un ejemplo. En el plano económico el Estado chileno ha proveído de beneficios tributarios $\mathrm{y}$ exenciones a los pequeños y medianos empresarios. ${ }^{99}$ En materia de desarrollo indígena se ha encargado de crear un estatuto indígena ${ }^{100}$ que intenta responder (otro tema es si lo ha logrado o no) a su deber de promover e instaurar la promoción de los derechos de los pueblos originarios

\footnotetext{
${ }^{97}$ Correa, Jorge, "Jurisprudencia del TC en materia de igualdad ante la ley. ¿Saliendo de la pura tautología?”, Anuario de derecho público, 2011, Nº 1 , p. 102.

${ }^{98}$ Nogueira, Humberto, "El derecho a la igualdad ante la ley, no discriminación y acciones positivas", Revista de derecho Universidad Católica del Norte, 2006, Vol. 13 N º 2, pp. 61-100.

${ }^{99}$ Ley 21.207, 2020.

${ }^{100}$ Ley 19.253, 1993.
} 
en consideración a sus diferencias con otros/otras personas dentro del Estado, en sentido positivo. Ambos cuerpos normativos son ejemplos de manifestaciones de primera tutela diferenciada, en que el Estado legislador es capaz de reconocer la diferencia para promover o aspirar al menos a un estado de igualdad real o efectiva. ¿La solución contraria supondría auxiliar de beneficios tributarios por ejemplo a los grandes consorcios empresariales? Ello derivaría obviamente en una mayor desigualdad tributaria, en una atrofia de las condiciones de competencia en la economía y nadie cuestionaría su inmoralidad. No vemos porqué, salvo retórica decimonónica obsesionada en los fines de la forma más que en el fin o función protector de la jurisdicción, no podamos aplicar estos mismos estándares de promoción y respeto por el trato racionalmente desigual en el ámbito procesal. Obviamente ello debe ir acompañado de las particularidades de seguridad que requiere el proceso y que ponen al proceso justo como el elemento guardián de la racionalidad y justicia de su desenvolvimiento.

\subsection{La dogmática comparada y la promoción de la técnica procesal idónea}

Sin perjuicio de lo que ya hemos dicho a propósito de la relación entre el componente axiológico de la TJE y su relación con la técnica procesal, conviene asentar la idea de que, por lo que se aboga no es por cualquier técnica sino por aquélla que sea capaz o apta para materializar derechos y hacerlos efectivos en la realidad. Es decir, se aboga también por el componente deóntico en el análisis de la técnica. De esta manera se recogen las diferencias de los casos concretos y en definitiva de las situaciones de facto diversas que pueden provocarse en el plano material.

Estas ideas, no tienen ninguna pretensión de novedad, como nada de lo que se ha planteado, pero eso no quita la motivación de introducir este enfoque sobre categorías que ya existen, de las cuales se habla o se ha hablado en otras realidades cercanas, integrantes también de nuestra tradición jurídica. La aspiración es a que éstas pueden redefinirse y utilizarse como un medio para elaborar, leer y adjudicar el derecho procesal desde la perspectiva del EDC, sin necesidad en lo deseable, de que dependan siempre de realizar reformas legislativas.

Esta idea de idoneidad o adecuación, en cuanto calificativo axiológico sobre la técnica procesal, se ha usado y se usa tanto para referirse a la técnica como para referirse a la tutela. Los primeros esbozos de ella parten de la 
obra del profesor italiano Andrea Рвото, quien fue capaz de detectar esta necesidad de idoneidad para que la efectividad pudiera prosperar. Llega a manifestar incluso en esta relación entre ambos calificativos (sumado a la oportunidad en que acaece la tutela) una relación condicional. ${ }^{101}$ Famosa es su frase, la tutela jurisdiccional "es efectiva o no es". ${ }^{102}$ Refleja plenamente el pensamiento del autor en tanto "la tutela jurisdiccional no es una forma abstracta, indiferente a las características de la situación sustancial necesitada de tutela, sino por el contrario, es un aspecto necesariamente concreto que se va modelando en torno a las particularidades y exigencias de protección de la situación jurídica sustancial cuya protección se pretende en el proceso". ${ }^{103}$

La reivindicación de la técnica propiamente tal y la conexión entre los calificativos deónticos referidos, en mi opinión es posible atribuirlo a la recepción de la doctrina contemporánea italiana por la dogmática brasileña de las últimas décadas, antes y más ahora desde la dictación del Código Procesal Civil de 2015. Particularmente en nuestros días, destacable es en este sentido la obra de Luiz Guilherme MARINONI. ${ }^{104}$ Es de hecho él quien separa estas categorías expresamente y postula que responden a criterios de clasificación diversa. ${ }^{105}$

Ya hemos expresado la visión de MARINONI sobre la técnica procesal y su necesidad de adecuación a la tutela del derecho material, y cómo esta idea forma parte del contenido del derecho fundamental a la TJE, por lo que nos remitimos a lo ya dicho.

De Oliveira, ha también propuesto la lectura de la actividad legislativa y judicial (técnica en sentido amplio) en miras de la eficacia normativa de los derechos fundamentales, señalando que "El propio proceso pasa así a ser el medio de formación del derecho, sea material o procesal, lo que se ve incrementado por la constatación de que el proceso debe servir para la producción de decisiones conforme a la ley; pero, además, dentro del marco de corrección, sirve esencialmente para la producción de decisiones

\footnotetext{
${ }^{101}$ Proto, cit. (n. 48), p. 12.

102 Proto, cit. (n. 48), p. 12

103 Proto, cit. (n. 48), p. 13.

${ }^{104}$ Es deber mencionar también a otros autores que forman parte de este movimiento como Daniel Mitidiero, Sergio Cruz Arenhart, Carlos Alberto De Oliveira, entre otros.

${ }^{105}$ MarinONI, Luiz Guilherme, cit. (n. 91) p. 53.
} 
justas". 106

En el Perú, Giovanni PrIORI, a quien debemos la traducción de varias obras de Andrea PROTO, reivindica la necesidad de entender a la TJE en base a la idea de idoneidad o adecuación de la tutela jurisdiccional. Postula que esta idoneidad debe ser material e instrumental.

La idoneidad material importa la disponibilidad de remedios legales adecuados para la lesión del derecho sustantivo y la actividad del Juez de otorgar ese remedio previsto por el ordenamiento abstracto confiriéndolo en el caso concreto, considerando las particularidades del caso. ${ }^{107}$

La idoneidad instrumental por su parte supone que el proceso debe ser el adecuado para brindar el remedio que el ordenamiento jurídico haya previsto para la protección del derecho material. ${ }^{108}$

En Argentina, Roberto BerIzOnCE, ha destacado que "la universalidad del proceso ordinario atenta contra la necesidad de tratamiento específico de las varias situaciones de derecho material. Como se ha señalado esa concepción se inspira en la ilusión de neutralidad del proceso en relación al derecho material, que llega a ser confundida con la autonomía del proceso. No cabe admitir, especialmente en el Estado cosntitucional de justicia, que el proceso civil vaya a desligarse del papel que el derecho material y los derechos fundamentales desempeñan en la sociedad". 109

Jorge PEYRANO, ha intentado darle una estructura de sistematización a estas técnicas que recogen la diferencia del caso concreto, señalando que son una realidad y que es posible evidenciarlas "cuando - excepcionalmente y a raíz de experimentar urgencias apremiantes el requirente del Servicio de Justicia o de las singularidades del derecho material cuya aplicación se reclama - se hubiera instrumentado un montaje procesal autónomo de cierta complejidad, portador de una pretensión principal y que cuenta con la dirección de un órgano jurisdiccional investido de facultades incrementadas e inusuales; estructura que deberá satisfacer, en la medida de lo razonable, la garantía del debido proceso (que ampara tanto al requirente del Servicio de Justicia como al requerido) y que se deberá apartar, en varios aspectos y

\footnotetext{
106 De Oliveira, cit. (n. 38), p. 191.

107 PrIORI, cit. (n. 27), p. 159.

${ }^{108}$ PrIORI, cit. (n. 27), p. 160.

109 Berizonce, Omar, "Fundamentos y confines de las tutelas procesales diferenciadas" Ius et Veritas, 2010, No 40, pp. 244-253.
} 
notoriamente, de las matrices vigentes clásicas". ${ }^{110}$

En Chile, poco se ha dicho al respecto, y esperamos poder abrir la discusión para montar al menos un andamiaje mínimo teórico sobre el cual puedan descansar técnicas o diseños procesales en pro de una mejor administración de justicia.

A propósito del análisis de una manifestación de las técnicas procesales anticipatorias, es posible encontrar en Chile, de a poco, la aparición de trabajos que abogan por la pretensión de corrección que implica la idoneidad o adecuación. Así, refiere Pozo, que "Los procedimientos tradicionales no son idóneos para atender a las nuevas situaciones sustantivas que requieren tutela o para adaptarse a los nuevos procedimientos que plantea la sociedad actual. La superación de estos obstáculos constituye un requisito esencial para garantizar a todas las personas el derecho fundamental a una tutela efectiva, de caso contrario, como lo señalábamos en un principio, si no existen mecanismos que hagan efectiva la aplicación de los derechos, su naturaleza viene degenerada a meras declaraciones de principios o buenas intenciones". ${ }^{111}$

Felipe RAYO, a propósito de un estudio sobre la técnica monitoria, también anuncia lo evidente, "debemos entender que el derecho a la jurisdicción no puede ser comprometido ni obstaculizado mediante las imposiciones de formalismos enervantes ni con interpretaciones de las formas procesales en un sentido contrario a la finalidad para la que se han establecido. Una actitud excesivamente formalista, del legislador o del órgano jurisdiccional, no es admisible. Las formalidades deben ser sólo aquéllas que aparezcan justificadas, legitimadas y proporcionadas conforme su finalidad". ${ }^{112}$

Un buen ejemplo, en sentido negativo, pero en pro del reconocimiento de la técnica procesal adecuada y su conexión a la efectividad, entrega JENKINS a propósito de la falta de idoneidad tutelar del procedimiento contenido en la ley 20.606 sobre medidas antidiscriminación conocido en Chile como "ley Zamudio". Afirma que "el Estado está en la obligación de ofrecer una protección jurisdiccional a las personas, no bastando para ello la

${ }^{110}$ Peyrano, Jorge, “¿Qué es y qué no es una tutela diferenciada, en Argentina?”, Revista peruana de derecho procesal, 2008, $\mathrm{N}^{\circ} 12$, pp. 229-244.

${ }^{111}$ Pozo, cit. (n. 82), p. 22.

${ }^{112}$ Rayo, Felipe, Proceso Monitorio Civil, Metropolitana, Santiago de Chile, 2012, p. 35. 
implementación legal de una simple acción judicial, sino que debe instaurar toda una maquinaria estatal (orgánica y procesal) dirigida a lograr la tutela efectiva de los derechos (una tutela intencionada) que responda sobre el fondo del asunto". ${ }^{113}$

Creo que, si bien el punto está hecho, es menester señalar que todas estas propuestas de integración de nuevos elementos a la efectividad de la TJ responden a una cuestión más general, que es la reivindicación que se viene postulando en la doctrina contemporánea de la conexión entre derecho material y derecho procesal. El estado actual del arte entre ambos planos es de disociación producto de las aspiraciones de autonomía tanto del proceso como de la acción, en tanto estructuras objeto de estudio disciplinar, que le dieron al Derecho Procesal contorno científico y su afiliación al Derecho Público. En hora buena que así fue, sin embargo, esa época ya pasó, y el extremo de este cientificismo, la forma y la idealización del proceso en tanto categoría llevaron al insularismo procesal respecto de las necesidades del derecho material.

TARUFFO graficó muy bien esta situación afirmando que el procesalista tipo ha abandonado el estudio del derecho material y su conexión al proceso. "Como máximo se reconoce, de acuerdo con la doctrina estándar, que el proceso tiene como finalidad la tutela y la aplicación del derecho, y, por tanto, tiene una función instrumental respecto de la aplicación concreta de las normas sustanciales". ${ }^{114}$

En definitiva "La justicia o equidad procedimental sustenta así la realidad de unión e interdependencia, no de dicotomía, entre sustancia y procedimiento. El énfasis en la dignidad individual ante los órganos del Estado, en especial el que acá se trata, el juez, se entiende como un derecho de dignidad del ser humano"115 y quien pretenda una disociación absoluta entre ambos planos, el material y el procesal, esta "desafiando la realidad". ${ }^{116}$

En algún modo, podemos recordar leyendo entre líneas a DE LA Oliva en este mismo camino, cuando se atrevió a ir contra la abstracción y a

\footnotetext{
${ }^{113}$ JenKINS, Gaspar, "La acción de no discriminación arbitraria a la luz de la tutela judicial efectiva", Estudios constitucionales, 2020, Vol. $18 \mathrm{~N}^{\circ} 1$, pp. 211-258.

114 TAruffo, Michele, "Derecho sustancial y procesal”, en: Priori, G. (coord.), Derecho Material y proceso, Palestra, Lima, 2017, pp. 13-20.

115 PÉrez, Álvaro, "El Impacto Del Diálogo Entre Derecho Sustantivo Y Derecho Procesal”, Revista de Derecho del Estado, 2018, $\mathrm{N}^{\circ}$ 41, p. 255.

${ }^{116}$ PÉrez, (n. 115), p. 258.
} 
reivindicar el derecho a la tutela jurisdiccional concreta; "por lo demás, raya en la evidencia que el derecho a la tutela jurisdiccional, no puede ser sino a una tutela concreta, al menos en el orden civil. La tutela jurisdiccional en abstracto sólo puede concebirse identificándola con la existencia de la jurisdicción en general, esto es, identificándola con el conjunto de dispositivos destinados a satisfacer ciertos derechos concretos cuando existan. No resulta proporcionado a lo que se prohíbe, ni mínimamente serio, prohibir la autotutela, y, a cambio, establecer tan sólo el simple derecho de acudir a una especie de oficina de reclamaciones, que resolverá sobre éstas sin preocuparse para nada de un inexistente derecho del reclamante a lo que reclama.

Me pregunto ¿existe algún/a justiciable que recurra al órgano jurisdiccional para obtener solo formas procesales abstractas? No encuentro argumentos para responder en sentido negativo. Nadie afirma la existencia de un derecho o interés sólo para buscar forma, éste es el instrumento; la función y finalidad es otra". ${ }^{117}$

La preocupación del caso concreto y sus particularidades es lo que orienta este tipo de lecturas o relecturas sobre las regulaciones iusfundamentales procesales. Éstas cuando consideran estos caracteres diferenciadores, adaptándose a las particularidades ha sido concebida bajo el rótulo de diferenciada, ${ }^{118}$ pues se aleja del tronco común que representa el marco rígido de la uniformidad procedimental. Esta diferenciación, aún ambigua entre nosotros, es la que Andrea Рвото cataloga en 1973 a propósito de un estudio sobre el proceso del trabajo en Italia, como "Tutela jurisdiccional diferenciada", ${ }^{119}$ abriendo sin duda un mundo de discusiones en torno a este concepto y sus significaciones y un apetito por parte de la doctrina latinoamericana de utilizarla en sus distintas manifestaciones. Esta conducta de encontrar en ella una vía hacia la efectividad no es sino muestra de la evidente precariedad que cruza todos nuestros sistemas procesales y que necesita de un sustento teórico, práctico e institucional de cara a transitar de las meras declaraciones al plano de la efectivización.

Estoy consciente de que se trata de una terminología aún ambigua que puede invocar a equívocos y por cierto a polémica. El propio padre de

\footnotetext{
${ }^{117}$ De la Oliva, cit. (n. 10), p. 12.

${ }^{118}$ MarinONI, (n. 11), RB-8.8.

${ }^{119}$ Рвото, cit. (n. 48), p. 12.
} 
la expresión así lo declara. ${ }^{120}$ Encontraremos este calificativo para referir procedimientos, técnicas, tutelas, instrumentos o mecanismos procesales. No obstante, hay una idea común detrás y aquello no puede negarse. Además, por mucho que el propio artífice de la expresión lo resista, principio de adquisición procesal de por medio, ya es parte del acervo cultural de la ciencia procesal contemporánea.

\section{CONCLUSIONES}

La efectividad de la tutela jurisdiccional es el eje sobre el cual se comprende a la potestad jurisdiccional en un Estado de Derecho Constitucional. Se trata de un calificativo axiológico que envuelve una promesa de materialización de los derechos subjetivos.

Para el cumplimiento de esta promesa constitucional, la eficiencia procesal juega un rol clave. Proponemos recuperar en dicho concepto el fin de justicia para el caso concreto, abandonando los criterios economicistas y releyéndolos desde la idoneidad de la técnica procesal.

Esta última, en tanto variable de la eficiencia procesal, se ha propuesto por parte de la doctrina comparada como necesaria condición de la efectividad jurisdiccional. En este sentido, la promesa constitucional de protección jurisdiccional efectiva contemplada en el Art. 19 numeral $3^{\circ}$ de la Carta de 1980 chilena no la contempla expresamente en su núcleo esencial. Sin embargo, es posible evidenciar la denuncia y necesidad de su incorporación desde los estudios comparados y nacionales sobre el punto. La textura abierta o porosa de las normas constitucionales chilenas que regulan la materia lo permiten en términos de adaptación a los tiempos y al desarrollo en transición de este derecho de naturaleza iusfundamental prestacional. Prueba de ello es el asentamiento reciente dentro del instituto, del derecho a la ejecución forzada.

La propia igualdad ante la ley, en una lectura actual, permite entender que la legislación y la jurisdicción deben reconocer en su ejercicio las diferencias relevantes para poder tender hacia una igualdad material y superar la mera igualdad formal, también propia del Estado de derecho decimonónico legal. La idoneidad o adecuación de la técnica procesal en

${ }^{120}$ РRoto, cit. (n. 48), p. 78. 
este sentido puede transformarse en una herramienta clave para este fin, incluso sin necesidad de reformas normativas.

No quisiera terminar sin proponer un ejemplo lo más sencillo y práctico posible respecto mi afirmación de prescindir incluso de reformas legales. El Art. 684 de nuestro actual Código de Procedimiento Civil establece la facultad del adjudicador de conceder provisionalmente lo pedido en la demanda sumaria, atendido que se cumplan copulativamente dos requisitos: a) que el demandado esté declarado rebelde atendida su incomparecencia a la audiencia de estilo y b) que se solicite esta anticipación por el actor con fundamento plausible.

La norma propone una medida que redistribuye el daño que provoca tiempo procesal habitualmente depositado en el demandante, ahora en el demandado, considerando su displicencia en la colaboración (aunque sea resistiendo la pretensión contraria). El derecho de defensa del demandado está disponible siempre mediante la oposición a esta concesión provisional mediante del artículo 684 inciso segundo. La técnica es equitativa respecto del tiempo procesal, existen requisitos claros desde el punto de vista legal, se justifica en la nula o precaria seriedad con que el demandado resguarda su propio derecho de defensa, y, sin embargo, es un hecho notorio y público entre los litigantes su prácticamente nula aplicación. La técnica procesal como parte de la TJE supone no solo la creación de reglas legales idóneas, sino que además la lectura y aplicación de estas reglas procesales conforme el tipo de situación ventilada en autos. Si el procedimiento sumario se aplica a situaciones que, aunque no urgentes, requieren de celeridad y una mayor premura, una interpretación y aplicación judicial restrictiva de medidas como la del Art. 684 inciso primero del Código de Procedimiento Civil, tornan en inidóneo el procedimiento completo. A la inversa, la adopción de este tipo de medidas, inspiradas en la consagración constitucional de la idoneidad en pro de efectividad, haría adecuado el conjunto de reglas del Art. 690 y siguientes para esas pretensiones que requieren de una tramitación rápida para que sean eficaces. 


\section{BIBLIOGRAFÍA CITADA}

\section{a) Doctrina}

Aldunate, Eduardo, Derechos fundamentales, Legal Publishing, Santiago de Chile, 2008.

Alexy, Robert, Teoría de los Derechos Fundamentales, Centro de Estudios Políticos y Constitucionales, Madrid, trad. de Bernal, Carlos, 2007, $2^{\circ}$ Edición.

Alvarado, Adolfo, Lecciones de Derecho Procesal Civil, Editorial Juris, Rosario, 2009.

Barona, Silvia, "A la búsqueda de la eficiencia y celeridad, claves de la justicia civil del siglo XXI", Libro homenaje al profesor Fábrega, Instituto colombo-panameño de Derecho Procesal, 2019, en http://dx.doi.org/10.2139/ ssrn.3511153, consultada: 26 de agosto de 2020.

Berizonce, Omar, "Fundamentos y confines de las tutelas procesales diferenciadas" Ius et Veritas, 2010, $\mathrm{N}^{\circ} 40$.

Berizonce, Omar, "Nuevos principios procesales y su recepción en ordenamientos jurídico-nacionales (influencia del derecho internacional y los derechos humanos)", Anales de la Facultad de Ciencias Jurídicas y Sociales de la Universidad Nacional de la Plata, 2012, $\mathrm{N}^{\circ} 42-9$.

Biblioteca del Congreso Nacional, "Actas Oficiales de la Comisión de Estudios de la Nueva Constitución Política de la República", Sesión 101², 30 de diciembre de 1974, T. III., https://www.bcn.cl/historiadelaley/historias-de-la-leyde-la-constitucion/, consultada el 5 de junio de 2021.

Bordalí, Andrés, "Análisis crítico de la jurisprudencia del Tribunal Constitucional sobre el derecho a la Tutela Judicial", Revista Chilena de Derecho, 2011, N ${ }^{\circ} 38-2$.

Bordalí, Andrés, Derecho Jurisdiccional, Ediciones Universidad Austral, Valdivia, 2016, $1^{\circ}$ Edición.

Capella, Juan Ramón, Elementos de Análisis Jurídico, Trotta, Madrid, 2006.

CORREA, Jorge, "Jurisprudencia del TC en materia de igualdad ante la ley. ¿Saliendo de la pura tautología?", Anuario de derecho público, 2011, N 1.

Contez, Gonzalo, La tutela cautelar en el proceso civil, Thomson Reuters, 2016, $1^{\circ}$ Edición.

De la Oliva, Andrés, Sobre el derecho a la tutela jurisdiccional. La persona ante la administración de justicia, derechos básicos, Bosch, Barcelona, 1980.

De Oliveira, Carlos Alberto, "El derecho a la tutela jurisdiccional efectiva desde la perspectiva de los derechos fundamentales", Revista de Derecho U. Austral de Chile, 2009, Vol. XXII, $\mathrm{N}^{\circ} 1$.

Do Santos, José, Efectividade do processo e técnica processual, Malheiro Editores, Sao Paulo, 2010, $3^{\circ}$ Edición.

Ferrada, Juan Carlos, "La Constitución económica de 1980", Revista de Derecho Universidad Austral de Chile, 2010, Vol. 11. 
García Amado, Juan Antonio, "Teorías del sistema jurídico y concepto de derecho", Anuario de Filosofía del Derecho, 1985, N ${ }^{\circ} 2$.

García, Gonzalo; Contreras, Pablo, "El derecho a la tutela judicial y el debido proceso en la jurisprudencia del Tribunal Constitucional chileno", Estudios Constitucionales, 2013, $\mathrm{N}^{\circ} 11-2$.

García, Ramón, Case Management, Tirant lo Blanch, Santiago de Chile, 2020.

HART, Herbert, El concepto de derecho, trad. de CARRIÓ, Genaro, AbeledoPerrot, Buenos Aires, 1963, $2^{\circ}$ Edición.

Hertel, Daniel, "Técnica processual e tutela jurisdicional: a instrumentalidade substancial das formas", Tesis de Magíster, Faculdade de Direito de Vitoria, Vitoria, publicada, 2004, http://191.252.194.60:8080/handle/fdv/38, consultada el 4 de junio de 2021.

JenKINS, Gaspar, "La acción de no discriminación arbitraria a la luz de la tutela judicial efectiva", Estudios constitucionales, 2020, Vol. $18 \mathrm{~N}^{\circ} 1$.

MARINONI, Luiz Guilherme, "Derecho a la tutela judicial de los derechos", en PRIORI, Giovanni, Derecho material y proceso, Palestra, Lima, 2017.

Marinoni, Luiz Guilherme, Técnica processual e tutela dos direitos, Thomson Reuters Brasil, São Paulo, 2019, $6^{\circ}$ edición (e-book).

Monroy, Introducción al proceso civil, Temis, Bogotá, 1996, T.I.

Navarro, Enrique, "El Debido Proceso en la Jurisprudencia del Tribunal Constitucional", Anuario de Derecho Constitucional Latinoamericano, 2013, ${ }^{\circ}$ 19.

Nogueira, Humberto, "El derecho a la igualdad ante la ley, no discriminación y acciones positivas", Revista de derecho Universidad Católica del Norte, 2006, Vol. $13 \mathrm{~N}^{\circ} 2$.

PÉrez, Álvaro, "Diálogo entre los derechos sustantivo y procesal: el puente de la justicia procedimental", en PRIORI, G. (coord.), Derecho Material y proceso, Palestra, Lima, 2017.

PÉrez, Álvaro, "El Impacto Del Diálogo Entre Derecho Sustantivo Y Derecho Procesal", Revista de Derecho del Estado, 2018, $\mathrm{N}^{\circ} 41$.

Peyrano, Jorge, “QQué es y qué no es una tutela diferenciada, en Argentina?”, Revista peruana de derecho procesal, 2008, $\mathrm{N}^{\circ} 12$.

Picó I JunOY, Joan, Las garantías constitucionales del proceso, Bosch, Barcelona, 2011, $2^{\circ}$ Edición. 1963.

Podetti, J. Ramiro, Teoría y técnica del proceso civil, Ediar, Buenos Aires,

Pozo, Felipe, La Tutela jurisdiccional anticipada en el proceso civil, Editorial Jurídica de Chile, 2013.

Priori, Giovanni, "Del derecho de acción a la tutela jurisdiccional de los derechos", Ius et Veritas, 2014, $\mathrm{N}^{\circ} 49$.

PrIori, Giovanni, El proceso y la tutela de los derechos, Fondo Editorial, 
Lima, 2019, $1^{\circ}$ Edición.

Proto, Andrea, La tutela jurisdiccional, Palestra, Lima, 2014, trad. de PrIORI, Giovanni, $1^{\circ}$ Edición.

Posner, Richard, El análisis económico del derecho, trad. de SuÁrez, Eduardo, Fondo de Cultura Económica, Ciudad de México, 2007.

Rayo, Felipe, Proceso Monitorio Civil, Metropolitana, Santiago de Chile, 2012.

Ross, Alf, Sobre el derecho y la justicia, Universidad de Buenos Aires, Buenos Aires, 1977, $4^{\circ}$ ed., trad. de CARrió, Genaro.

Rossatti, Horacio, El derecho a la jurisdicción antes del proceso, Depalma, Buenos Aires, 1984.

Stordeur, Eduardo, Análisis económico del derecho. Una introducción, Abeledo Perrot, Buenos Aires, 2011.

TARUffo, Michele, "Derecho sustancial y procesal", en: Priori, G. (coord.), Derecho Material y proceso, Palestra, Lima, 2017.

TARuffo, Michele, Páginas sobre justicia civil, Trad. de Aramburo, Maximiliano, Marcial Pons, Madrid, 2009.

VARGAs, Macarena, El derecho a la ejecución forzada: noción e implicancias a partir de la jurisprudencia de la Corte Europea de Derechos Humanos, Ediciones Universitarias de Valparaíso, Valparaíso, 2019.

Vigo, Rodolfo, Perspectivas Iusfilosóficas Contemporáneas, AbeledoPerrot, Buenos Aires, 2019, $3^{\circ}$ edición.

Zalgrebelsky, Gustavo, El Derecho dúctil, Trotta, Madrid, 2011, trad. de Gascón, Marina, $10^{\circ}$ Edición.

\section{b) Normativa}

- Constitución Política de la República de Chile.

- $\quad$ Código Civil de Chile, 1856.

- $\quad$ Ley 1.552, Código de Procedimiento Civil, 1903.

- $\quad$ Ley 7.421, Código Orgánico de Tribunales, 1943.

- Ley 21.207, Establece medidas tributarias y financieras destinadas a apoyar a las micro, pequeñas y medianas empresas, 2020.

- $\quad$ Ley 19.253, Establece normas sobre protección, fomento y desarrollo de los indígenas, y crea la Corporación Nacional de Desarrollo indígena, 1993.

c) Jurisprudencia

- $\quad$ Corte Suprema, 3 de julio de 2018, Rol 5098-2017.

- $\quad$ Corte Suprema, 3 de enero de 2020, Rol 29.767-2019.

- Tribunal Constitucional, 22 de marzo de 2013, Rol 2.411-13.

- Tribunal Constitucional, 9 de julio de 2020, Rol 8.452-20.

- $\quad$ Tribunal Constitucional, 25 de junio de 2020, Rol 7.587-19. 